\title{
Criteria and Scale for Argumentation
}

\author{
Chamnong Kaewpet \\ Rajamangala University of Technology Krungthep, Bangkok, Thailand
}

\begin{abstract}
This paper presents an updated and practical criteria and scale for teaching, learning, and evaluating argumentation. The ability criteria and scale is generated from existing knowledge of argumentation as expected by CEFR, TOEFL and IELTS, as well as recent interest in argumentation. Examination of the academic literature suggests that the new criteria and scale should consider relevancy, reasoning, language use, organization and writer's voice. Relevancy has not yet been seriously highlighted in the existing criteria. Reasoning, language use and organization are common criteria in argumentation. Writer's voice is not emphasized in the existing criteria but often discussed in recent publications on argumentation. It is added to the updated framework in this paper to keep up with advancements in the field. This new framework could be a powerful option for teaching, learning and evaluating argumentation particularly in EFL or ESL contexts.
\end{abstract}

Index Terms - argumentation, criteria, scale, relevancy, reasoning, language use, organization, writer's voice

\section{INTRODUCTION}

EFL or ESL learners, generally speaking, have not demonstrated adequate ability in written tasks demanded by high-stake English standardized tests. The test results are usually insufficient or merely close to required scores. According to a 2015 record by IELTS (2017), the writing mean band score of students from an EFL country was only 5.5, while the total score was 9. This score is not enough for a test taker to get a letter of offer from a university in the United Kingdom, or to be qualified for a job at an oil company, for example, because one would need a 6.5 IELTS overall score to be accepted (IELTS, 2016). Argumentation plays a role in the English standardized tests. It is required to write one of the two required tasks. It is not only important for English standardized tests, but also for success in daily life, education and careers. It assists in accomplishing many purposes - to persuade others during casual discussions, to convince other people, to change behaviors, to make important decisions, to ask for a direct action, to gain support, to give/receive consultations, to negotiate business, or to resolve differences of opinions (Bipinchandra, Shah, Puteh, Din, Rahamat\& Aziz, 2014; Deane \& Song, 2014; Liu \& Stapleton, 2014). For these reasons, argumentation has been emphasized in many syllabuses and studies on writing around the world - America (Dean \& Song, 2014), China (Liu \& Stapleton, 2014), and Chile (Preiss, Castillo, Flotts \& Martin, 2013). Research has reported positive influences of many instructional techniques on students' ability in argumentation including group discussions, public Internet discussion forums and critical questions (Reznitskaya, Anderson \& Kuo, 2007; Ritchie \& Black, 2012; Song \& Ferretti, 2013). This paper is interested in a different and hardly explored area, namely, ability criteria in the field of argumentation. It aims to create an up-to-date and practical criteria and scale, which could be a powerful option for teaching, learning and evaluating argumentation.

The exploration in this paper will start from 1) a scheme of argumentation, originally created by Toulmin in 1958, which has brought much of the attention to argumentation; 2) a description of the Common European Framework of References for Languages (CEFR) B2 ability level, which specifically identifies argumentation at this level; 3) an introduction to one of the two required tasks of three high-stake English standardized tests - TOEFL, IELTS and TOEIC; and 4) findings of a review of recent research publications and discussions in the field of argumentation. This paper will conclude with a new and practical argumentation ability and scale generated from the existing literature.

\section{SCHEME OF ARGUMENTATION}

Argumentation originated thousands of years ago with the ancient Greeks, when Aristotle classified the means of persuasion into ethos, pathos and logos. Ethos appeals to authorities; pathos appeals to emotion; logos appeals to logic (Dean \& Song, 2014). This system of classification became widespread when Stephen Toulmin introduced his scheme of argumentation, which embraced consideration for those who disagreed with the writer (Qin \&Karabakak, 2010; Ramage, Bean \& Johnson, 2010). Recently, Stapleton and Wu (2015) employed an adapted version of these elements to analyze argumentative essays written by high school students in Hong Kong. The adapted elements comprise several categories including claims or "an assertion in response to a contentious topic or problem." The next element is data, or "evidence to support a claim [which] can take various forms such as facts, logical explanations, suppositions, statistics, anecdotes, research studies, expert opinions, definitions and analogies." The third element is called counter-argument, which includes "possible opposing views that can challenge the validity of a writer's claim." Counter-argumment data or evidence can be used "to support a counter-argument claim." Rebuttal claims refer to "statements in which the writer responds to a counter argument." Finally, rebuttal data refers to "evidence to support a rebuttal claim which includes the 
identification of possible weaknesses in the counter-argument claim, data or assumptions, such as logical fallacies, insufficient support, invalid assumptions and immoral values (citing Ramage\& Bean 1999, p. 22)."

The framework was employed successfully in Stapleton and Wu's study, where five types of qualities were found. Before the study, Qin and Karabakak (2010) successfully used six elements to investigate the relationship between the elements and the overall quality of argumentative papers written by second-year university English major students. They found that counter-argument claims, counter-argument data, rebuttal claims, and rebuttal data were significant predictors of the overall quality of the papers. For these reasons, the six elements are regarded as essentials for effective criteria and scale for teaching, learning and evaluating argumentation.

\section{ARgumentation In CEFR}

CEFR (Cambridge ESOL, 2011) describes language learners' ability in four language skills - speaking, reading, listening and writing. It divides ability into six levels: A1 Breakthrough, A2 Waystage, B1 Threshold, B2 Vantage, C1 Effective Operational Proficiency, and C2 Mastery. These levels can be grouped into three main sub-levels with two sub-divisions, that is, Basic User (A1 and A2), Independent User (B1 and B2), and Proficient User (C1 and C2). B2 is further divided into two sub-classes that can be called Lower B2 and Upper B2. Argumentation is identified in relation to communicative language activities at Upper B2. These specifications are relative to three kinds of communicative competences. Communicative language activities include writing an essay which "develops an argument, giving reasons in support of or against a particular point of view and explaining the advantages and disadvantages of various options" and "[synthesizing] information and arguments from a number of sources" (Council of Europe, 2001, p. 62). The three kinds of communicative competences are linguistic, socio-linguistic, and pragmatic competences. Linguistic competences are concerned with general linguistic range, vocabulary range, vocabulary control, grammar accuracy, and orthographic control. The socio-linguistic competences focus on socio-linguistic appropriateness. The pragmatic competences deal with thematic development, coherence and cohesion (Council of Europe, 2001).

CEFR was established in 1971 and a full framework was distributed in 2001 as a result of the need for a common international framework for language learning, teaching and assessment, which could facilitate co-operation among educational institutions in the international community. Since the creation of the framework, it has been used to design syllabuses, examinations or textbooks and to set minimum language requirements both inside and outside Europe. It has been translated into 40 languages (Cambridge ESOL, 2011; Council of Europe, 2001). In Thailand, it is a recommended framework by the Ministry of Education. Thai undergraduate students are expected to be equipped with English proficiency at the B2 level as a minimum (Office of the Higher Education Commission, Ministry of Education, 2016). Therefore, it is considered in this paper that argumentation in the CEFR perspective should be taken into account when creating criteria and a scale for teaching, learning, and evaluating argumentation.

\section{TOEFLTASK}

Test of English as a Foreign Language (TOEFL) measures all four language skills. The writing test consists of two tasks. Argumentation is significant in the second task, where test takers employ reason to support their choice of position, namely, to agree or disagree with a given statement. Test takers have to complete a 300 word essay within a 30-minute time limit. Each skill in TOEFL is measured separately. The independent writing task is scored for development, organization, grammar and vocabulary. An essay at the top score of 5, for example,1) addresses a given topic and task effectively; 2) is organized and well developed; 3) displays unity, progression, and coherence: and 4) displays consistent facility in the use of language(ETS-TOEFL, 2015).

TOEFL was initially launched in 1964. It measures the English language ability of non-native speakers. Its main application has always been for applying to study in English-speaking countries. According to ETS, TOEFL has been recognized by more than 9,000 colleges, universities and agencies in more than 130 countries, including the United States, Canada, the United Kingdom and Australia. Currently, it is used to acquire Australian or New Zealand work visas. In order to pursue postgraduate study at the East-West Center University-Hawaii in the United States or to be qualified to work in New Zealand, for example, one needs an internet-based TOEFL score of 79 (Educational Testing Service-TOEFL, 2016). TOEFL is one of the most influential tests to assure the English proficiency of English learners. Therefore, its criteria should also be taken into consideration when creating an updated criteria and scale.

\section{IELTS TASK}

The International English Language Testing System (IELTS) is one of the pioneers in four-skill English language testing. It has two versions: 1) Academic - for people who apply for higher education or professional registration; and 2) General training for those who want to migrate to Australia, Canada or the United Kingdom, or apply for secondary education, a training program or work experience in an English-speaking environment. The writing section in both versions requires test takers to complete two tasks. The second task assesses argumentative ability: "...you will be asked to write an essay in response to a point of view, argument or problem." The difference in the two versions is that the academic test demands a formal style of writing, while the general training test is open to personal style (IELTS, 2016). Test takers are instructed to write approximately 250 words and spend less than 40 minutes to complete the task. 
The essays are measured on task achievement, coherence and cohesion, lexical resources, grammatical range and accuracy. The written performance is classified into nine bands. For example, the highest band, 9, is described as follows: 1) task achievement: "fully addressed all parts of the task, presents a fully developed position in answer to the question with relevant, fully extended and well supported ideas;" 2) coherence and cohesion: "uses cohesion in such a way that it attracts no attention, skillfully manages paragraphing;" 3) lexical resource: "uses a wide range of vocabulary with very natural and sophisticated control of lexical features, rare minor errors occur only as slips;" 4) grammatical range and accuracy: "uses a wide range of structures with full flexibility and accuracy, rare minor errors occur only as slips" (IELTS, 2016).

IELTS was jointly established in 1989 by the British Council, IDP-IELTS Australia, and Cambridge English Language Assessment. It is an international standardized test of English language proficiency for non-native English language speakers. IDP-IELTS Australia is currently managing a network of more than 100 test centers in more than 60 countries. Over 2.9 million tests were taken in 2016. It is accepted for study and work purposes across the globe. It is also a requirement for immigration purposes in Australia, Canada, New Zealand and the United Kingdom. One would need a 6.5 IELTS score, for example, to apply for a postgraduate study at the University of Birmingham in the United Kingdom or to work at Abu Dhabi National Oil Company in the United Arab Emirates (IELTS, 2016, cf. section I.). IELTS is a very influential tool for determining the English ability of English learners. Therefore, its criteria should also be taken into account in designing an updated criteria and scale for teaching, learning, and evaluating argumentation in this paper.

\section{TOEIC TASK}

Test of English for International Communication (TOEIC) tests English-language skills used in the workplace. It has two versions: listening and reading is the first one and speaking and writing is the second. The first version is referred to more frequently. This study is concerned with the second version. The writing test includes three different task types. This study is primarily concerned with the third task in which the test taker has to write an opinion essay. The writer must choose one of the given options and give reasons for it. Argumentation is, in fact, a form of opinion. The difference between argumentation and general opinion is that the former approach employs opposing views, while this might not be the case in an opinion paper. Inclusion of opposing views has been proven to increase quality of argumentation (e.g., Qin \&Karabakak, 2010). Therefore, TOEIC test takers should aim to include argumentation in their written task. TOEIC test takers have to complete an opinion essay of about 300 words within 30 minutes. The essay is scored for the use of supporting reasons, examples given, as well as grammar, vocabulary, and organization. Scores of the three writing tasks are summed up. The highest score at level 9 is described as follows: Test takers at level 9 can 1) "communicate straightforward information effectively and use reasons, examples, or explanations to support an opinion;" 2) "when using reasons, examples, or explanations to support an opinion, their writing is well-organized and well developed;" 3) "the use of English is natural, with a variety of sentence structures, appropriate word choice, and is grammatically accurate;" and 4) "when giving straightforward information asking questions, giving instructions, or making requests, their writing is clear, coherent, and effective" (Educational Testing Service-TOEIC, 2016).

TOEIC has been used to recruit and promote employees since 1979. ETS reports that today TOEIC scores are used by nearly 14,000 companies, government agencies and English language learning programs in 150 countries. For example, they are used to recruit staff at Packard Bell in France where a quality technician needs a TOEIC score of 650, while a buyer must have a TOEIC score of 850. At the LG Group, TOEIC score standards have been set to track learning progress in English-language training courses and to determine employees' readiness for promotion (ETS-TOEIC, 2016). A search on JobDB.com (2016), an online job application website, found that 665 out of 21,500 positions included TOEIC requirements in their job advertisements. Because TOEIC is powerful in terms of job application, its criteria should also be taken into account when devising a criteria and scale for teaching, learning and evaluating argumentation in this paper.

\section{RECENT INTEREST IN ARGUMENTATION ABILITY}

Interest related to criteria for evaluating argumentation ability in recent publications is mostly the same as reported in the scheme of argumentation and English standardized tests: reasoning, language use, organization, as well as two additional areas, namely, relevancy, and writer's voice.

\section{A. Relevancy}

Relevancy in this paper is concerned with the extent to which the response has addressed a given controversial situation or issue. The term is used in Stapleton and Wu's study (2015) as one main criterion to evaluate the quality of reasoning of Hong Kong high school students' argumentative essays (cf. section II). Their study evaluates whether or not a given statement is relevant to a claim. In addition to the scenario, anyone teaching English in non-English speaking environments would understand that sometimes students do not comprehend the test question and that has resulted in a mismatch between the question and answer. This paper also aims at EFL or ESL situations; therefore, relevancy has become an important criterion. 


\section{B. Reasoning}

Reasoning is the heart of argumentation, because what matters most in argumentation are arguments. An argument, defined for the general public, is "a reason or reasons why you support or oppose an idea or suggestion, or the process of explaining them" (Cambridge Dictionaries Online 2013). The influence of reasoning on the quality of argumentation can be understood particularly from studies on the elements of argumentation reported in section II. Particularly, Qin and Karabakak's study (2010) suggested that inclusion of four of the six elements in argumentation would contribute to its quality, namely, counter-argument claim, counter-argument data, rebuttal claim, and rebuttal data. In fact, the presence or absence of possible opposing views, or, in other words, counter-argument claim and counter-argument data, was one of the criteria used to evaluate quality in the study. In another study, Stapleton and Wu (2015) embarked on analysis of the quality of reasoning. They focused on this aspect because an essay with a good structure, built with all six elements of argumentation, may not ensure acceptability of the given reasons. Therefore, reasoning is another important criterion in argumentation and is taken into account in the present paper.

\section{Language Use}

Language use is concerned mainly with grammar and vocabulary. This includes the range of use and control over them. An interesting grammatical point introduced in argumentation is 'problematizing phrases' such as "It may/could/might be argued/asserted/contended/maintained/claimed/said that...," with the purpose to make a statement about the opposing position appears debatable and possibly untrue (Daly, 1997). In vocabulary, the three basic types of words suggested by DataWorks Educational Research (2017) deserve attention: academic vocabulary, content vocabulary and support vocabulary. Academic vocabulary should be given importance, because argumentation, for English learners, functions mostly in academia. Content vocabulary should also be taken into account, because the nature of argumentation is discussions in particular topic areas. Support vocabulary should be considered, because it helps with full comprehension of the argumentation text. For EFL or ESL learners, this paper is interested in effective use, rather than correctness of grammar and vocabulary.

\section{Organization}

Interest in organization focuses on three main areas: organizational patterns, cohesion and coherence. Common organizational patterns, as observed from model argumentation, are in a deductive style. In this style, the writer's position regarding a controversial issue is announced at the beginning of the essay, and then a chain of reasons or explanations are given for the position (e.g., Daly, 1997; Hawthorn English Language Centres, 1997). At the same time, cohesion functions to organize relevant information orderly and binds a text as a unified whole (Yang \& Sun, 2012). It is a property of a text and is usually carried out through cohesive devices such as references, conjunctions, ellipsis/substitution, and lexical cohesion (IELTS, 2007; Yang \& Sun, 2012; Bastukmen \& Randow, 2014). Use of cohesive devices does not always ensure cohesion (Crossley, Kyle, \& McNamara, 2016); therefore, effective use of these devices is important. For the third criteria, coherence is concerned with unity and continuity of the discourse (Kern 2000), or how the text develops and how the ideas and information inter-relate (Basturkmen \&Randow, 2014). In this sense, it is "not texts but rather people that cohere when understanding texts" (Lorenz, 1999, p. 2). Coherence is the only factor investigated in all educational levels including postgraduates in recent research (e.g., Basturkmen \& Randow, 2014); therefore, it should always be an important criterion of argumentation.

\section{E. Writer's Voice}

An additional criteria to consider is writer's voice or authorial voice, which the audience or reader should truly feel. Writer's voice has not been highlighted in CEFR, TOEFL, IELLTS, and TOEIC, but has often been investigated in recent research. Liu (2013) investigated language use that influences writer's voice. This includes appraisal of resources, consisting of attitude, engagement and graduation. Liu found that the highly-rated essays investigated in the study employed appraisal resources to foreground authorial voice and position readers successfully. Meanwhile, three other studies have looked into features of writer's voice that influence the writing quality or voice strength (Helms-Park \& Stapleton, 2003; Yoon, 2017, Zhao, 2017). The features of writer's voice included assertiveness, self-identification and reiteration (Helms-Park \& Stapleton, 2003). In fact, writer's voice is an important construct in L1 writing, but has not been taken into account in L2, due to the belief that it does not fit some L2 learners, particularly those who come from collectively-oriented cultural backgrounds (Yoon, 2017). However, English learners nowadays have plentiful options to communicate with people internationally. They should learn ways to perform well in the same medium of communication.

\section{CONClusion: CRiteria ANd SCALE FOR ARgumentation}

Underpinned by the scheme of argumentation originally created by Toulmin in 1958, the demand for argumentation by CEFR, TOEFL, IELTS, TOEIC, and interest in recent publications, argumentation quality criteria and scale is shown in Table I. 
TABLE I.

ARGUMENTATION QUALITY CRITERIA \& SCALE

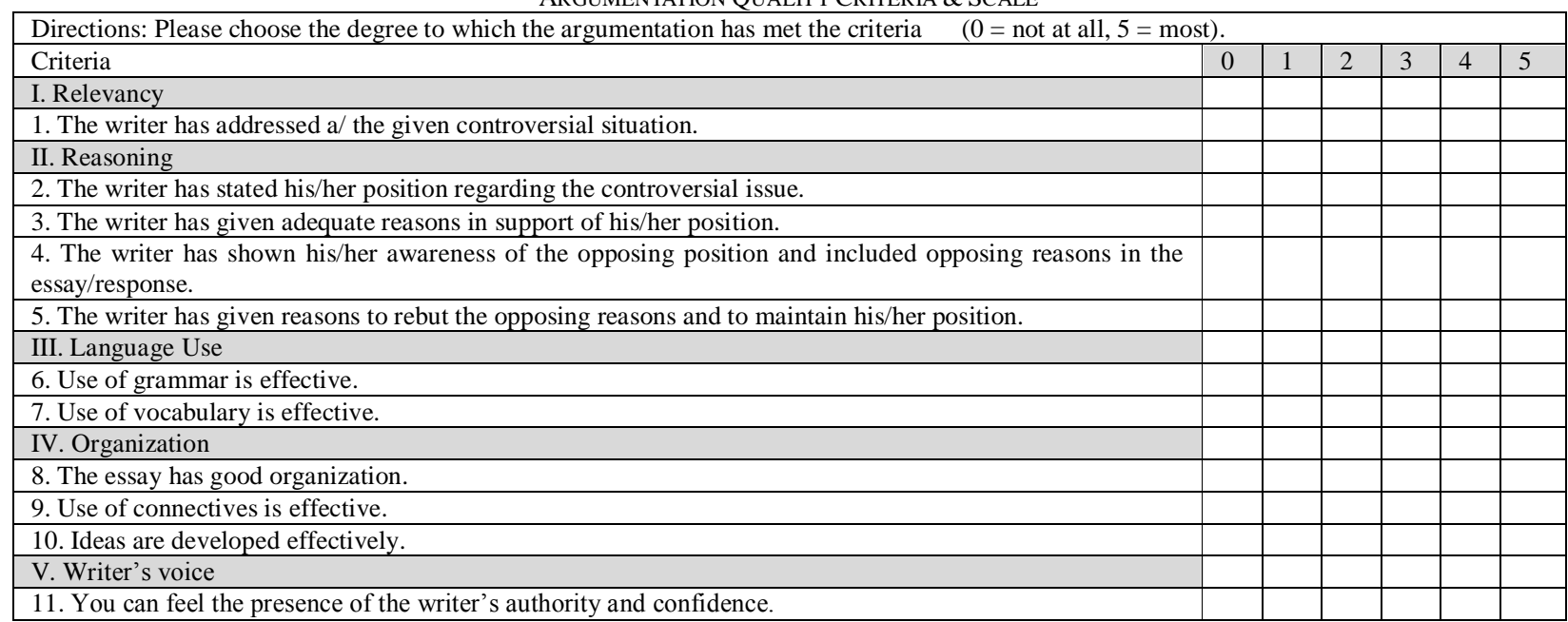

This framework has been updated and created for advancement in the field of argumentation. It has been constructed to be as practical as possible for all users - instructors, students and evaluators. It is also less abstract than other criteria, which mostly take a holistic approach. The concept of relevancy in this framework is originally from Stapleton and Wu (2015), and extended in this paper (cf. section VI). Reasoning is always the focal point of argumentation (Toulmin 1958, cited in Qin \& Karabakak, 2010; Qin \&Karabakak, 2010; Stapleton \& Wu, 2015). The skills of reasoning have been revised and adapted in countless contexts and emphasized in all scenarios since it was first recommended by Aristotle in ancient Greece (Dean \& Song, 2014). The focus of language use - grammar and vocabulary - is on effectiveness rather than correctness. It is really challenging for EFL or ESL learners to produce an error-free piece. The focus on effectiveness optimizes a channel of reasoning for students. Like language use, this criteria and scale is open to any organizational patterns that writers see fit, as long as the organization helps with coherence and the development of ideas. Use of connectives is taken as a separate item, because their proper use usually casts a positive influence on the quality of argumentation (Liu \& Braine, 2005; Yang \& Sun, 2012; Qin \& Uccelli, 2016). Finally, writer's voice has been added to the criteria and scale because it has been discussed frequently in recent publications. Therefore, writers should learn to project their voice clearly in argumentation. This criteria and scale can be useful for teaching, learning, and evaluation of argumentation. It can also be used for further research, or further examination to strengthen the proposed framework.

\section{REFERENCES}

[1] Basturkmen, H. \& Randow, J. v. (2014). Guiding the reader (or not) to re-create coherence: Observations on postgraduate student writing in an academic argumentative writing task. Journal of English for Academic Purposes. 16, 14-22.

[2] Bipinchandra, J. S., Shah, P. M., Puteh, S. N., Din, R., Rahamat, R. \& Aziz, J. A. (2014). User needs analysis in learning argumentative writing via mobile platform. Procedia Social and Behavioral Sciences. 118, 198-205.

[3] Cambridge Dictionaries Online (2013). Argument. http://dictionary.cambridge.org/ (accessed 26/5 2013).

[4] Cambridge ESOL 2011. Using the CEFR: Principles of Good Practice. http://www.cambridgeenglish.org/Images/126011-using-cefr-principles-of-good-practice.pdf (accessed 11/3/ 2016).

[5] Council of Europe. (2001). Common Europe Framework of Reference for Languages: Learning, Teaching, Assessment. http://www.coe.int/t/dg4/linguistic/Source/Framework_EN.pdf (accessed 11/3/ 2016).

[6] Crossley, S.A., Kyle, K. \& McNamamura, D.S. (2016). The development and use of cohesive devices in L2 writing and their relations to judgments of essay quality. Journal of Second Language Writing. 32, 1-16.

[7] Daly, B. (1997). Writing Argumentative Essays. Available: http://www.ltn.lv markie/essaywriting/frntpage.htm (accessed 2/11/2008).

[8] DataWorks Educational Research. (2016). Vocabulary Development Part 1: Types of Vocabulary. https://dataworks-ed.com/blog/2014/07/vocabulary-development-part-1-types-of-vocabulary/ (accessed 15/12/2016).

[9] Deane, P. \& Song, Y. (2014). A case study in principled assessment design: designing assessments to measure and support the development argumentative reading and writing skills. Psicologia Educavita. 20, 99-108.

[10] Educational Testing Service-TOEIC (2016). For Workplace. https://www.ets.org/toeic (accessed 25/4/ 2016).

[11] ETS-TOEFL. (2015). The TOEFL Test. https://www.ets.org/toefl (accessed 23/4/2015).

[12] ETS-TOEIC. (2016). Data and Analysis 2016. www.iibc-global.org/library/toeic_data/toeic/pdf/TOEIC_Program_DAA.pdf (accessed 12/12/ 2016).

[13] Hawthorn English Language Centres. (1997). IELTS to success. Queensland: John Wiler \& Sons.

[14] Helms-Park, R. \& Stapleton, P. (2003). Questioning the importance of individualized voice in undergraduate L2 argumentative writing: An empirical study with pedagogical implications. Journal of Second Language Writing. 12, 245-265.

[15] JobDB.com. (2016). Search. https://th.jobsdb.com/th (accessed 10/1/ 2016).

[16] IELTS. (2016). About Us. https://www.ielts.org/ (accessed 12/4/ 2016). 
[17] IELTS. (2017). Test Taker Performance 2015. https://www.ielts.org/teaching-and-research/test-taker-performance (accessed $12 / 1 / 2017)$.

[18] Kern, R. (2000). Literacy and language teaching. Oxford: Oxford University Press.

[19] Liu, M. \& Braine, G. (2005). Cohesive features in argumentative writing produced by Chinese undergraduates. System. 33, 623-636.

[20] Liu, F. \& Stapleton, P. (2014). Counterargumentation and cultivation of critical thinking in argumentative writing: investigating washback from a high-stakes test. System. 45, 117-128.

[21] Lorenz, G. (1999). Learning to cohere: Causal links in native vs. non-native argumentative writing. In Bublitz, W., Lenk, U. \&Ventola, E. (eds.). Coherence in spoken and written discourse: How to create it and how to describe it. Amsterdam: John Benjamns, 55-76.

[22] Liu, X. (2013). Evaluation in Chinese university EFL students' English argumentative writing: an appraisal study. Electronic Journal of Foreign Language Teaching. 10, 40-53.

[23] Office of the Basic Education Commission, Ministry of Education 2014). Policy on Teaching and Learning English. http://english.obec.go.th/english/2013/index.php/th/component/attachments/download/67 (accessed 15/10/ 2016).

[24] Preiss, D. D., Castillo, J. C., Flotts, P. \& Martin, E. S. (2013). Assessment of argumentative writing and critical thinking in higher education: Educational Correlates and Gender Differences. 28: 193-203.

[25] Qin, J. \& Karabacak, E. (2010). The analysis of Tomlin's elements in Chinese EFL university argumentative writing. System. $38,444-456$.

[26] Qin, W. \&Uccelli, P. (2016). Same language, different functions: A cross-genre analysis of Chinese EFL learners' writing performance. Journal of Second Language Writing. 33, 3-17.

[27] Ramage, J. D., Bean, J. C., \& Johnson, J. (2010). Writing arguments: A rhetoric with readings. Hong Kong: Pearson Longman.

[28] Reznitskaya, A., Anderson, R.C. \& Kuo, L. (2007). Teaching and learning argumentation. The Elementary School Journal. 107, 449-472.

[29] Ritchie, M. \& Black, C. (2012). Public internet forums: Can they enhance argumentative writing skills of second language learners? Foreign Language Annuals. 45, 349-361.

[30] Song, Y. \& Ferretti, R. P. (2013). Teaching critical questions about argumentation through the revising process: Effects of strategy instruction on college students' argumentative essays. Read Writ. 26, 67-90.

[31] Stapleton, P. \& Wu, Y. (2015). Assessing the quality of arguments in students' persuasive writing: A case study analyzing the relationship between surface structure and substance. Journal of English for Academic Purposes. 17, 12-23.

[32] Yang, W. \& Sun, Y. (2012). The use of cohesive devices in argumentative writing by Chinese EFL learners at different proficiency levels. Linguistics and Education. 23, 31-48.

[33] Yoon, H. (2017). Textual voice elements and voice strength in EFL argumentative writing. Assessing Writing. 32, $72-84$.

[34] Zhao, C. G. (2017). Voice in timed L2 argumentative essay writing. Assessing Writing. 31, 73-83.

Chamnong Kaewpet is an assistant professor at Faculty of Liberal Arts, Rajamangala University of Technology Krungthep, where she teaches argumentation and independent study to Thai students. She obtained a doctoral degree from Melbourne University, Australia. Her research interests lie primarily in the same area as the teaching. She can be contacted at chamnong.k@mail.rmutk.ac.th. 